\title{
Receptor-Type Tyrosine-Protein Phosphatase T
}

National Cancer Institute

\section{Source}

National Cancer Institute. Receptor-Type Tyrosine-Protein Phosphatase T. NCI

Thesaurus. Code C37315.

Receptor-type tyrosine-protein phosphatase T (1441 aa, $162 \mathrm{kDa}$ ) is encoded by the human PTPRT gene. This protein is involved in cell-cell adhesion, signal transduction and protein dephosphorylation. 